\title{
Multiple Dissipative Devices for Blast-Resisting Cable-Supported Glazing Façades
}

\author{
Claudio Amadio and Chiara Bedon \\ Department of Engineering and Architecture, University of Trieste, Piazzale Europa 1, 34127 Trieste, Italy \\ Correspondence should be addressed to Chiara Bedon; bedon@dicar.units.it
}

Received 27 May 2013; Accepted 16 September 2013

Academic Editor: Laurent Mevel

Copyright (C) 2013 C. Amadio and C. Bedon. This is an open access article distributed under the Creative Commons Attribution License, which permits unrestricted use, distribution, and reproduction in any medium, provided the original work is properly cited.

The paper analyzes the structural response of a high-level air blast loaded cable-supported façade. Since the glass panels and the cables present a typical brittle behavior and are subjected to elevated tensile stresses when a high-level explosion occurs, multiple dissipative devices are simultaneously introduced in the conventional glazing system to mitigate the maximum effects of the design blast wave. Dynamic analyses are performed using a sophisticated FE-model to describe accurately the response of the façade equipped by dissipative devices. Based on numerical results of previous contributions, viscoelastic spider connectors (VESCs) are introduced in the points of connection between glass panels and pretensioned cables, to replace "rigid" spider connectors commonly used in practice. At the same time, rigid-plastic frictional devices (RPDs) are installed at the top of the bearing cables to mitigate furthermore the bracing system. As a result, due to the combined use of VESCs and RPDs opportunely calibrated, the maximum tensile stresses in the glass panels and in the cables appear strongly reduced. In addition, the proposed devices do not trouble the aesthetics of such transparent structural systems. At last, simple design rules are presented to predict the response of cablesupported façades subjected to high-level dynamic loads and to preliminary estimate the mechanical parameters of combined VESCs and RPDs.

\section{Introduction}

The effects of air blast loads on the dynamic behaviour of glazing façades constitute a topic of great interest and actuality. Because of this reason, numerous authors recently focused on the typical behaviour of simply supported glass plates subjected to explosions, providing interesting analytical formulations [1-4]. In [5, 6], Wei and Dharani proposed a energy-based failure criterion for laminated glass panes subjected to blast loads, useful to predict the breakage of glass and the size of possible glass shards. Larcher et al. [7], as well as Hooper et al. [8], numerically simulated the behavior of laminated glass panels supported by metallic frames and loaded by air blast waves. In their finite-element (FE) models, the possible cracking of glass was taken into account. Weggel and Zapata [9] and Weggel et al. [10] investigated the dynamic behaviour of a nearly conventional laminated glass curtain wall with split screw spline mullions subjected to low-level blast loading. A unitized curtain wall subjected to high-level blast loads has been recently studied also in [11], and the structural effects of a dissipative system composed of viscoelastic devices introduced in conventional rigid steel brackets have been investigated. An advanced parametric study has been recently performed on laminated glass window elements under blast loads [12].

Teich et al. [13] focused on the structural response of a cable-net façade subjected to air blast loads, highlighting the influence of the negative phase pressure on the global response of similar glazing systems. Wellershoff et al. [14, 15] focused on the development of glass clamp-cable connectors and cable-end connectors able to work as crash absorbers and to plasticize in blast enhanced cable-supported façades.

As highlighted also in [16, 17], cable-supported façades subjected to explosions present a typical behaviour that strongly differs from the dynamic response of conventional curtain walls or buildings. In them, the glass panels represent the primary source of damage, since they mainly absorb the incoming energy due to the explosive blast wave. At the same 
time, the glass panels transfer elevated forces to the other components of the façade (connectors, bearing cables) and to the structural backup.

Based on numerical results of previous contributions [16, 17], the paper investigates the behavioural trends of a cablesupported façade subjected to high-level blast loads (Level DGSA [18]) by means of numerical simulations and analytical predictions. To improve the global dynamic response of the examined façade, multiple dissipative devices are introduced in the traditional glazing system. Firstly, viscoelastic spider connectors (VESCs) are introduced at the points of connection between the cables and the laminated glass panels. At the same time, rigid-plastic frictional devices (RPDs) are simultaneously installed at the top of the supporting cables to mitigate them further. In this manner, due to VESCs, the air blast pressure acting on the façade does not completely transform into elastic energy stored by the harmonic steel cables, but VESCs partly absorb and dissipate them; thus, the maximum tensile stresses in glass panes and cables strongly decrease. An additional reduction of maximum forces in the cables can be provided by RPDs, which allow dissipating a part of the incoming energy due to the sliding of two metallic surfaces in contact. Finally, simple analytical formulations are presented to constitute a preliminary design approach for similar cable-supported systems.

\section{Cable-Supported Glazing Façade}

The studied façade consists in $1.55 \mathrm{~m} \times 3.00 \mathrm{~m}, 10 / 4.52 / 10 \mathrm{~mm}$ laminated glass panels, obtained by assembling two fully tempered glass sheets and a middle PVB-film [16, 17]. The façade is assumed $L=9.00 \mathrm{~m}$ tall and large enough to study a singular $1.55 \mathrm{~m} \times 9.00 \mathrm{~m}$ modular unit $(B \gg L$, Figure 1$)$. High carbon content harmonic steel cables (diameter $\phi=$ $36 \mathrm{~mm}$, axial stiffness $k_{\text {cable }} \cong 11300 \mathrm{kN} / \mathrm{m}$ ) subjected to an initial pretension $H_{0}=300 \mathrm{kN}$ support the cladding wall.

Each laminated glass panel is six-point fixed, by means of four-hole (corners) and two-hole spider connectors (midspan of the vertical edges; Figure 1). The typical spider (Figure 2) consists of a stainless steel four-hole (or two-hole) crossbar linked to the glass panels through metallic fasteners (e.g., rotules). A stainless steel supporting bar connects the crossbar to the pretensioned cable. As a result, the spider constitutes a "rigid" connector for the cladding wall.

Commonly, as in the studied example, four-hole spider connectors are introduced at the corners of glass panels, so that four panels could be contemporarily constrained (Figure 1). Similarly, two-hole spider connectors are introduced at the midspan of glass sheets edges, in order to provide intermediate supports between adjacent panels (Figure 1). In any case, both the typologies of spider connectors provide the same pointconstraint to glass sheets, as schematized in Figure 2.

When subjected to high-level air blast loads, a similar facade undergoes large deflection and is affected by elevated tensile stresses in the glass panels as well as in the bearing pretensioned cables $[16,17]$. Although explosions represent an exceptional loading condition for buildings, the possible

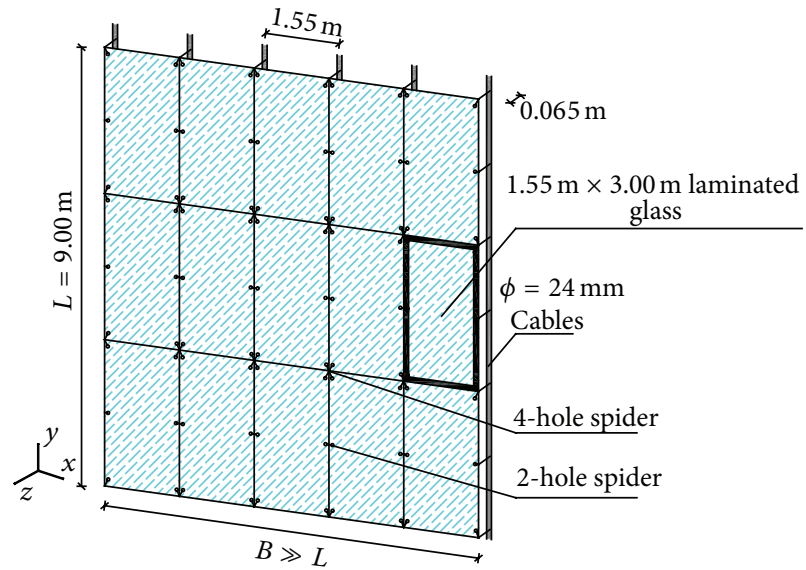

FIGURE 1: Schematic view of the studied cable-supported façade.

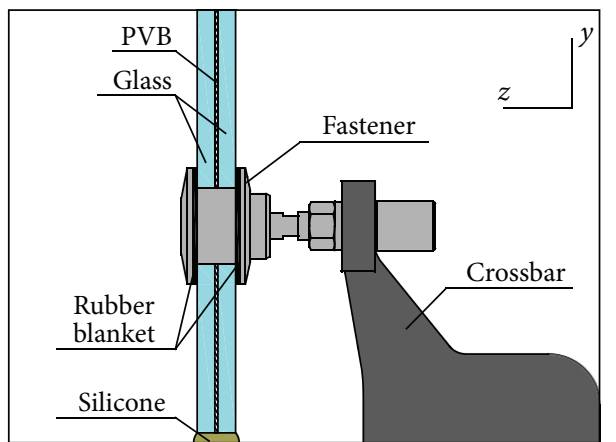

FIgURE 2: Four-hole rigid spider connector. Cross-section detail of point support.

collapse of the curtain wall should be avoided. In this context, as proposed in the following sections, opportunely designed dissipative devices could be successfully introduced in the points of connection between the glass panels and the cables, as well as in the points of connection between the cables and the structural backup. In this manner, the global dynamic response of the façade due to high-level blast pressures could be improved and cracking of glass panes could be avoided with obvious benefits for the stability of the entire cladding wall.

2.1. Viscoelastic Dissipative Spider Connectors (VESCs). The primary characteristic and the main effectiveness of the proposed viscoelastic system consists in the partly absorption/dissipation of the incoming energy due to explosions and in the mitigation of the main components of the curtain wall, especially the glass panes. A similar effect can be achieved by introducing viscoelastic devices in substitution of conventional "rigid" spider connectors [16]. The result, as proposed in Figure 3, consists in a spider connector equipped by viscoelastic devices (VESC).

The efficiency of a similar mechanism directly depends on the dissipative capabilities of the used viscoelastic layer. Polymers, glassy materials, natural rubber, or rubbers with 


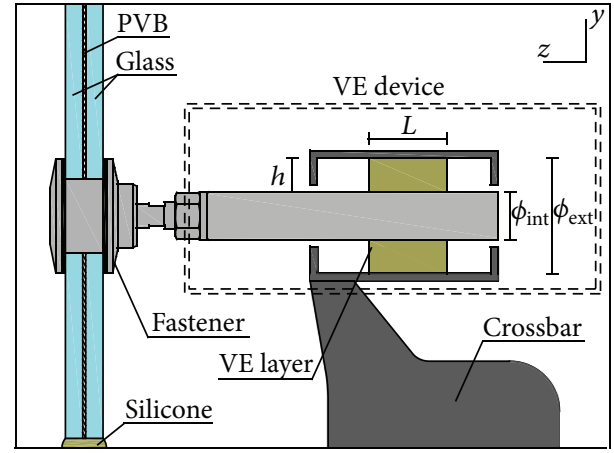

FIGURE 3: Cross-section of a possible four-hole VESC (detail of point support with viscoelastic device).

additives able to dissipate energy if subjected to shear deformations are largely used in engineering applications. Generally, the effectiveness of a viscoelastic device is expressed in terms of stiffness $k_{d}$ and damping ratio $c_{d}$, which are related to the mechanical characteristics and to the size of the dissipative layer. Specifically, the damping ratio is associated to the stiffness $k_{d}$ as [16]

$$
c_{d}=\frac{\eta k_{d}}{\omega}
$$

where $\omega$ is the operating frequency of the system. In this work, as well as in [16] the mechanical properties of a rubber with high dissipative capabilities were taken into account $\left(G^{\prime}=\right.$ $1 \mathrm{MPa}, \eta=0.6$ ). In addition, to not trouble the aesthetic of the studied façade, the dissipative layer was considered $h^{\mathrm{VESC}}=$ $0.02 \mathrm{~m}$ thick and $L^{\mathrm{VESC}}=0.03 \mathrm{~m}$ long $\left(k_{d}=283 \mathrm{kN} / \mathrm{m} \cong\right.$ $\left.k_{\text {cable }} / 40, c_{d}=3.4 \mathrm{kN} \mathrm{s} / \mathrm{m}\right)$. As a result, when the explosion occurs, the inner cylinder slides through the external one and the viscoelastic system partly absorbs and dissipates the incoming blast energy (Figure 3).

In these hypotheses, an optimal calibration of the rigidity $k_{d}$ is fundamental to maximize the structural effectiveness of a similar mechanism. Generally, if the used viscoelastic devices have an excessive stiffness $k_{d}$, the damping ratio $c_{d}$ increases (1), but unavoidably VESCs behave as conventional rigid spider connector. In contrary, if the stiffness $k_{d}$ of each viscoelastic device is not sufficiently elevated, when a highlevel explosion occurs VESCs would undergo an excessive sliding $s_{\max }^{\text {VESC }}$. To avoid the cracking of the viscoelastic layer, their maximum shear strain $\gamma_{\max }^{\mathrm{VESC}}=s_{\max }^{\mathrm{VESC}} / h^{\mathrm{VESC}}$ should be limited to $\gamma_{\max }^{\mathrm{VESC}} \cong 2 \div 2.5$, thus, leading to a limit sliding $s_{\max }^{\mathrm{VESC}} \cong 0.05 \mathrm{~m}$. Nevertheless, it should not be ignored that the effectiveness of VESCs is directly proportional to their sliding. The higher is the sliding $s_{\max }^{\mathrm{VESC}}$ and the higher is the dissipation of the incoming energy due to air blast loading, therefore, the higher is the mitigation of the components of the façade-module.

As highlighted in [16], the effectiveness of similar devices explains in strongly cutting down the maximum tensile stresses occurring in the glass panes, in presence of high-level explosions as well as ordinary dynamic loads. In addition,

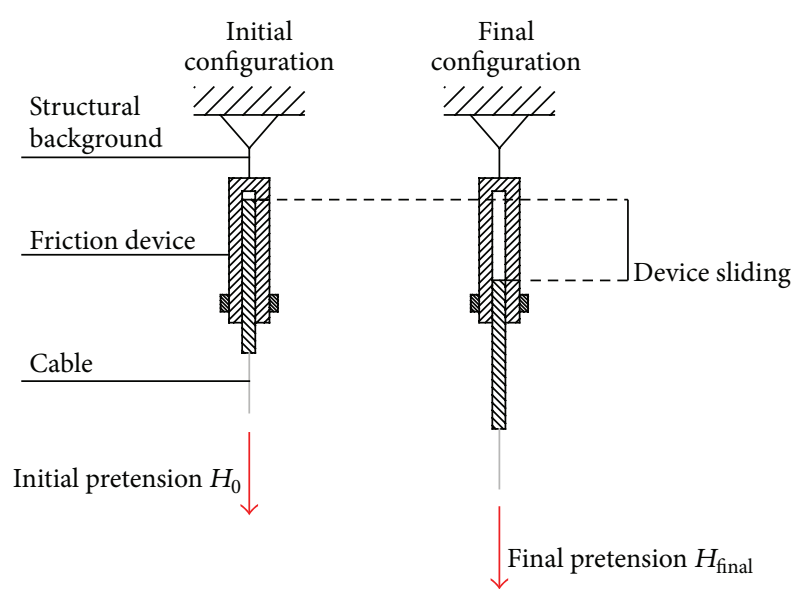

FIGURE 4: Frictional device and working scheme (cross-section).

since VESCs dissipate a part of the incoming energy due to the external impulse, the façade can be considered subjected to a "reduced" design blast wave; consequently, the maximum axial forces occurring in the cables, as well as the maximum deflection of the facade, can be obviously reduced.

2.2. Frictional Rigid-Plastic Devices (RPDs). The second typology of dissipative devices consists in a frictional system to be installed at the top (or at the bottom) of pretensioned cables [17]. The primary characteristic of the proposed rigid-plastic frictional devices (RPDs) consists in limiting the axial forces in the cables to a preestablished maximum value. The sliding of two metallic surfaces in contact guarantees a similar effect; consequently, the parameter able to describe their dynamic behaviour is the sliding force $F_{s}$. Generally, a frictional device consists in three metallic plates joined together by a series of pretensioned bolts and a slotted hole. Two outer plates and the bearing structure are joined together, whereas the middle plate is connected to the cable (Figure 4).

If the external axial load is higher than $F_{s}$, the frictional device starts sliding; thus, it reduces maximum axial forces in the cable and it partly dissipates in heat the input energy. As a result, the frictional device exploits its effectiveness only in specific blast loading scenario, whereas it provides a rigid connection to the bearing cables in presence of low-intensity explosions or ordinary loads [17]. Particular attention should be dedicated to the design of similar devices. In fact, as it would be expected, the sliding of the metallic plates in contact causes a loss of pretension in the bearing cables; thus, if their sliding force is not opportunely calibrated, the facade could collapse. In addition, differing from VESCs, frictional devices do not allow mitigating the glazing surface. However, as proposed in the following sections, the use of RPDs in combination with VESCs could maximize the effectiveness of both the mechanisms.

2.3. Blast Load. A numerical code developed at University of Trieste was used to describe the time varying-pressure blast wave characterizing a high-level (Level-D of GSA) air blast load [18]. As proposed in Figure 5, the corresponding 


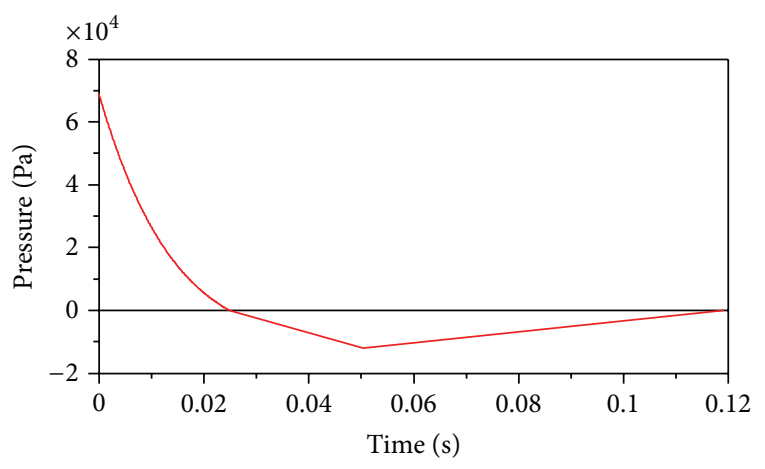

Blast load-GSA Level D

FIGURE 5: Blast loading time-varying pressure functions (Level DGSA [18]).

pressure-time curve consists in a triangular pulse, which instantaneously reaches its maximum value (static overpressure peak $p_{r}^{D}=68.9 \mathrm{kPa}$ ) and decays to zero pressure in a relatively short positive phase (duration $t_{d}^{D}=0.025 \mathrm{~s}$ ). Based on numerical simulations performed in $[16,17]$, only the positive phase of the design blast load was taken into account in performed dynamic incremental analyses.

\section{FE-Modelling of the Façade with Viscoelastic Spider Connectors and Frictional Devices}

According with the schematic layout proposed in Figure 1, the studied façade was modelled using the finite element computer program ABAQUS/Explicit [19] and a single modular unit consisting in three $10 / 4.52 / 10 \mathrm{~mm}$ laminated glass panels, a series of half viscoelastic spider connectors, a pair of pretensioned cables, and two frictional devices was taken into account in numerical simulations (Figure 6(a), and $[16,17]$ ).

Laminated glass panels were described by means of 410 four-node three-layer composite shell elements (S4R). Glass was assumed as an isotropic linear-elastic material, whereas for the PVB-film an elastoplastic characteristic curve was taken into account (yielding stress $\sigma_{y, \mathrm{PVB}}=8 \mathrm{MPa}$ and failure strain $300 \%$ [20]). Harmonic steel of cables, as well as stainless steel constituting the connectors of the facade-module, were assumed to behave linear elastically, as summarized in Table 1.

The pretensioned cables were modelled in the form of truss elements (T3D2, 12 elements) having a cross-section area equal to half the nominal one. The initial pretension force was applied by imposing a vertical displacement at the base of the cables. Only $U_{z}$ displacements were allowed for all the cable nodes. At the same time, the frictional devices were introduced in the FE-model of the façade module in the form of axial connectors joined at the top of each cable and rigidly connected to the structural backup (Figure 6). To describe the typical cyclical response of similar devices in presence of high-level air blast loads, a rigid-plastic characteristic curve was defined in ABAQUS. Based on the results of preliminary simulations, a value $F_{s}=650 \mathrm{kN}=2.15 H_{0}$ was taken into account for the sliding force of each RPD.

Each half-VESC was described as a conventional rigid spider connector equipped by two (four-hole spider) or one (two-hole spider) viscoelastic devices, according with their geometry (Figure 1) and distribution along the height of the FE-model (Figure 6(a); white dots for two-hole spider connectors and black dots for four-hole spider connectors). As a result, each half VESC consists, respectively, in three (fourhole) or two (two-hole) rigidly connected beams (B31, 24 elements) joined together by means of a weld connector able to provide a fully bonded connection between the relative displacements and rotations of the spider components $\left(u_{x}=\right.$ $u_{y}=u_{z}=0$ and $\left.r_{x}=r_{y}=r_{z}=0\right)$. Based on the discussed modelling assumptions, the supporting bar of each VESC is described by means of a B31 beam element having a crosssection area equal to half the nominal one.

All the connector nodes were opportunely constrained, in accordance with the expected behaviour of the single façade-module; therefore, only $U_{z}$ displacements and $R_{x}$ rotations were allowed under blast load. Since the façade was assumed large enough $(B \gg L)$ to neglect its lateral restraints (Section 2), the same boundary conditions were ensured also for the nodes composing the glass panels.

The modelled spiders allow the glass panels interacting with the vertical cables by means of join connectors, prohibiting possible relative displacements in the interested nodes $\left(u_{x}=u_{y}=u_{z}=0\right)$. The single viscoelastic device is then introduced in the FE-model in the form of a linear elastic axial spring (Figure 6(b), detail of half four-hole VESC). To avoid excessive sliding in each viscoelastic device, the presence of additional rigid blocks, modelled in the form of a nonlinear axial spring working in parallel with the first one, was taken into account. To avoid the breaking of the viscoelastic layer, the maximum sliding $s_{\max }^{\mathrm{VESC}}$ of this spring, having zero initial stiffness until the reaching of $s_{\max }^{\mathrm{VESC}}$, was set equal to $s_{\max }^{\mathrm{VESC}}=0.05 \mathrm{~m}$.

Finally, although negligible, a total damping ratio $\xi_{\mathrm{TOT}}=$ $2.9 \%[16,17,21]$ was introduced in FE-model as a Rayleigh mass proportional damping to simulate the possible effects of structural, aeroelastic, and PVB-material damping.

3.1. Results of Nonlinear Dynamic Analyses. Numerical analyses were performed on the FE-model of the facade-module equipped by VESCs and RPDs to study the behavioural trends of the glazing system subjected to a Level D-GSA blast load and to highlight the structural benefits involved by the use of multiple devices. All the analyses had a total duration of $1.1 \mathrm{~s}$. The initial instants $(0<t<0.10 \mathrm{~s})$ were used to impose the initial pretension force to the cables. In the subsequent instants $(0.10 \mathrm{~s}<t<1.10 \mathrm{~s})$ a Level D-blast load was applied to the glass surface in the form of a uniformly distributed, impulsive load $q_{\text {blast }}^{D}$ representative of the positive phase of the time-pressure function proposed in Figure 5. To ensure the accuracy of numerical results, the maximum time step was set equal to $0.00001 \mathrm{~s}$. Once the dynamic explicit procedure was completed, the used mean time increment 

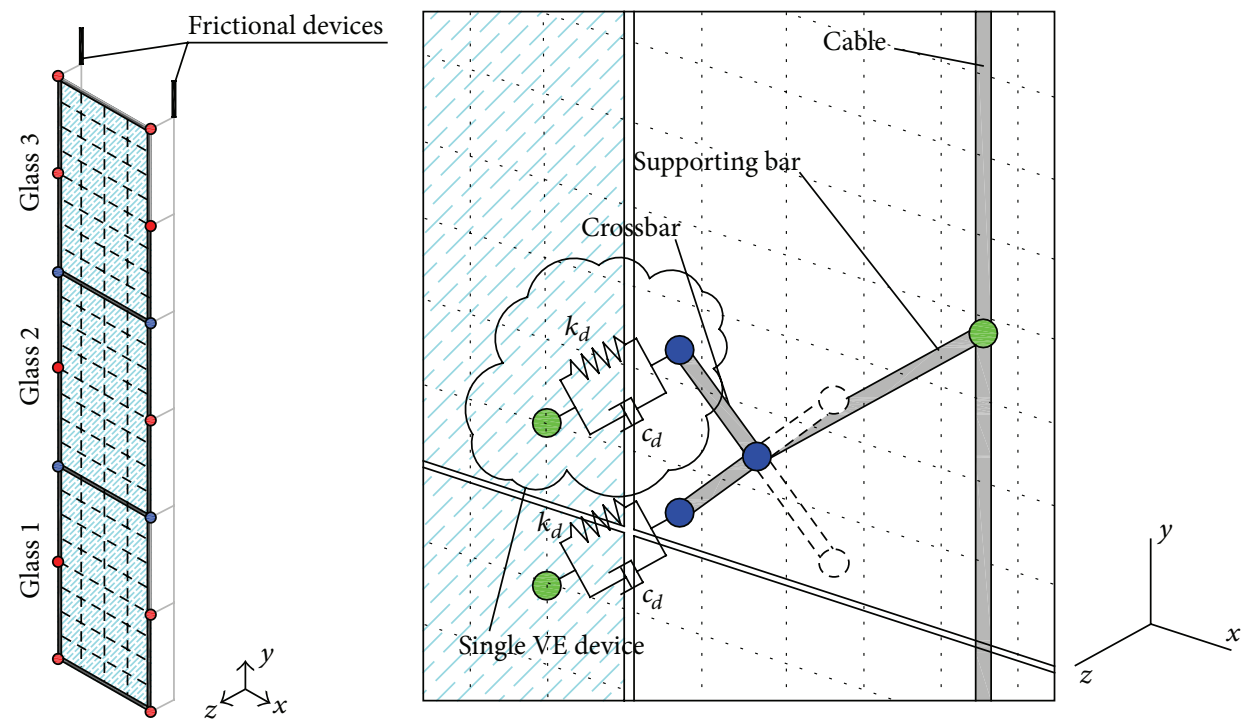

- 2-hole VESCs

Join $\left(u_{x}, u_{y}, u_{z}\right)$

- 4-hole VESCs

Weld $\left(u_{x}, u_{y}, u_{z} ; r_{x}, r_{y}, r_{z}\right)$

(a)

(b)

FIGURE 6: FE-model (a) and detail of half four-hole VESC (ABAQUS) (b).

TABLE 1: Material properties (ABAQUS).

\begin{tabular}{lcccc}
\hline & Young's modulus & Poisson's ratio & Density & Behaviour \\
& {$\left[\mathrm{N} / \mathrm{m}^{2}\right]$} & {$[-]$} & {$\left[\mathrm{kg} / \mathrm{m}^{3}\right]$} & 2490 \\
\hline Glass panes & $7 \times 10^{10}$ & 0.23 & 1100 & Linear elastic \\
PVB & $5 \times 10^{8}$ & 0.50 & 7300 & Elastoplastic \\
Harmonic steel (cables) & $1.3 \times 10^{11}$ & 0.32 & Linear elastic \\
Stainless steel (connectors and devices) & $2.1 \times 10^{11}$ & 0.32 & 7300 & Linear elastic \\
\hline
\end{tabular}

TABLE 2: Numerical results of dynamic analyses (ABAQUS). Level D-GSA.

\begin{tabular}{|c|c|c|c|c|}
\hline & Glass tensile stress (L1) & Glass tensile stress (L2) & Glass tensile stress (L3) & Cable deflection \\
\hline Devices & $\begin{array}{c}\sigma_{\text {glass,max }} \\
{[\mathrm{MPa}]}\end{array}$ & $\begin{array}{c}\sigma_{\text {glass,max }} \\
{[\mathrm{MPa}]}\end{array}$ & $\begin{array}{c}\sigma_{\text {glass,max }} \\
{[\mathrm{MPa}]}\end{array}$ & $\begin{array}{c}u_{\text {cable, } \max } \\
{[\mathrm{m}]}\end{array}$ \\
\hline No devices & 138.18 & 89.30 & 83.40 & 0.44 \\
\hline VESCs & 85.73 & 58.18 & 47.94 & 0.41 \\
\hline VESCs + RPDs & 88.60 & 35.15 & 49.15 & 0.44 \\
\hline
\end{tabular}

TABLE 3: Numerical results of dynamic analyses (ABAQUS). Level D-GSA.

\begin{tabular}{|c|c|c|c|c|c|}
\hline Devices & $\begin{array}{l}\text { Cable axial force (max.) } \\
\qquad \begin{array}{c}H_{\text {cable, } \max } \\
{[\mathrm{kN}]}\end{array}\end{array}$ & $\begin{array}{c}\text { Cable axial force (min.) } \\
H_{\text {cable,min }} \\
{[\mathrm{kN}]}\end{array}$ & $\begin{array}{c}\text { VESCs displacement } \\
s_{\max }^{\mathrm{VESC}} \\
{[\mathrm{m}]}\end{array}$ & $\begin{array}{c}\text { VESCs shear strain } \\
\gamma_{\max }^{\mathrm{VESC}}=s_{\max }^{\mathrm{VESC}} / h^{\mathrm{VESC}} \\
{[-]}\end{array}$ & $\begin{array}{c}\text { RPDs sliding } \\
s_{\max }^{\mathrm{RPD}} \\
{[\mathrm{m}]}\end{array}$ \\
\hline No devices & 858 & 302 & - & - & - \\
\hline VESCs & 798 & 306 & 0.0450 & 2.25 & - \\
\hline VESCs + RPDs & 658 & 115 & 0.0415 & 2.08 & 0.0165 \\
\hline
\end{tabular}

resulted equal to $0.000003 \mathrm{~s}$. The main results obtained by the performed dynamic incremental analyses are summarized in Tables 2 and 3. Additional interesting comparisons are proposed in Figures 7-11, in terms of maximum tensile stresses in the middle glass panel (glass 2 and locations L1, L2, and L3), maximum axial forces in the vertical cables and maximum deflections. To emphasize the effectiveness of each typology of device, results obtained for the façademodule not equipped by VESCs or RPDs are compared with numerical simulations performed for the same façade module with only VESCs or equipped by multiple devices (VESCs and RPDs). 

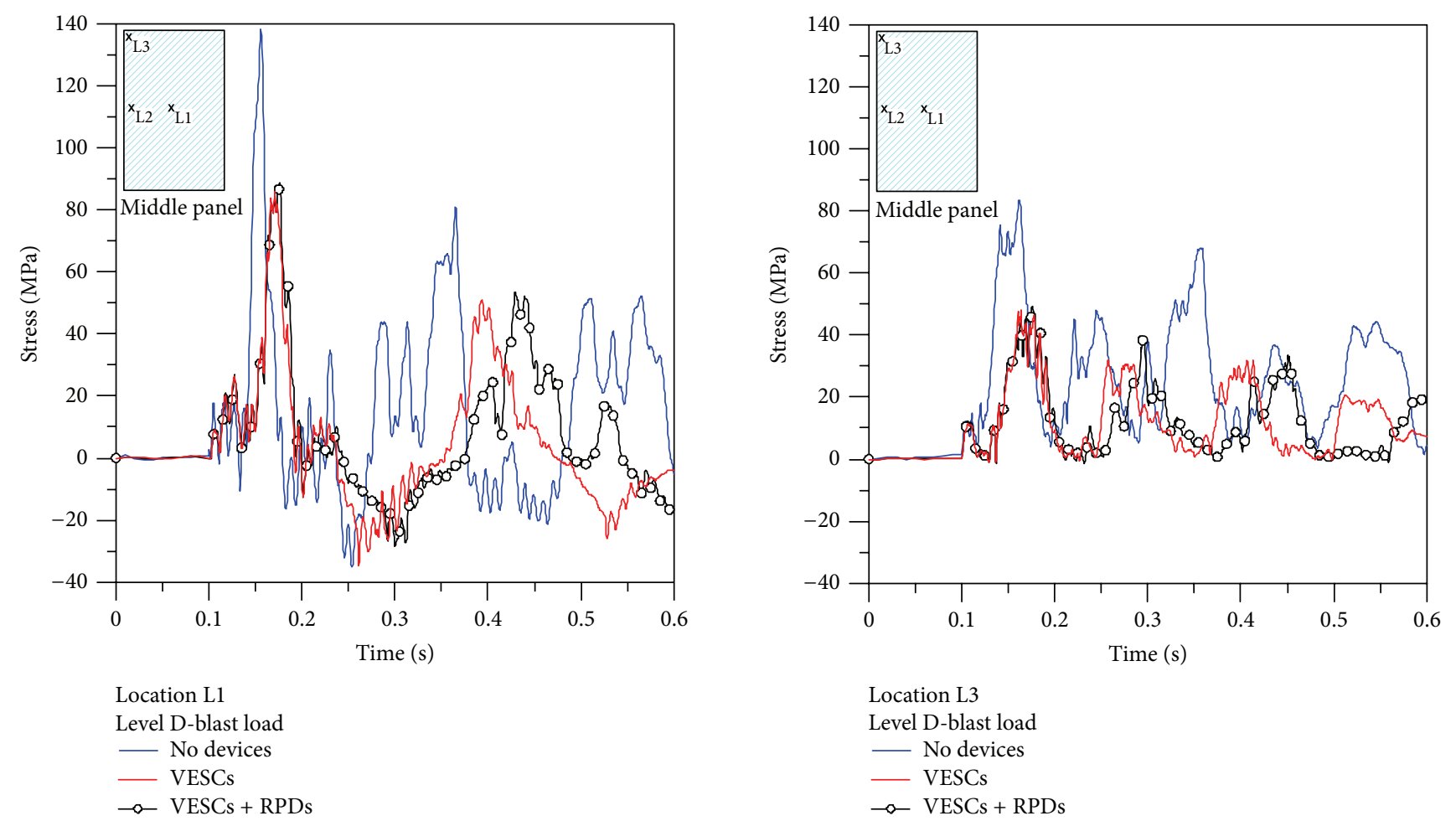

FIgURE 7: Tensile stresses in the middle glass panel, as a function of time (ABAQUS). Location L1.
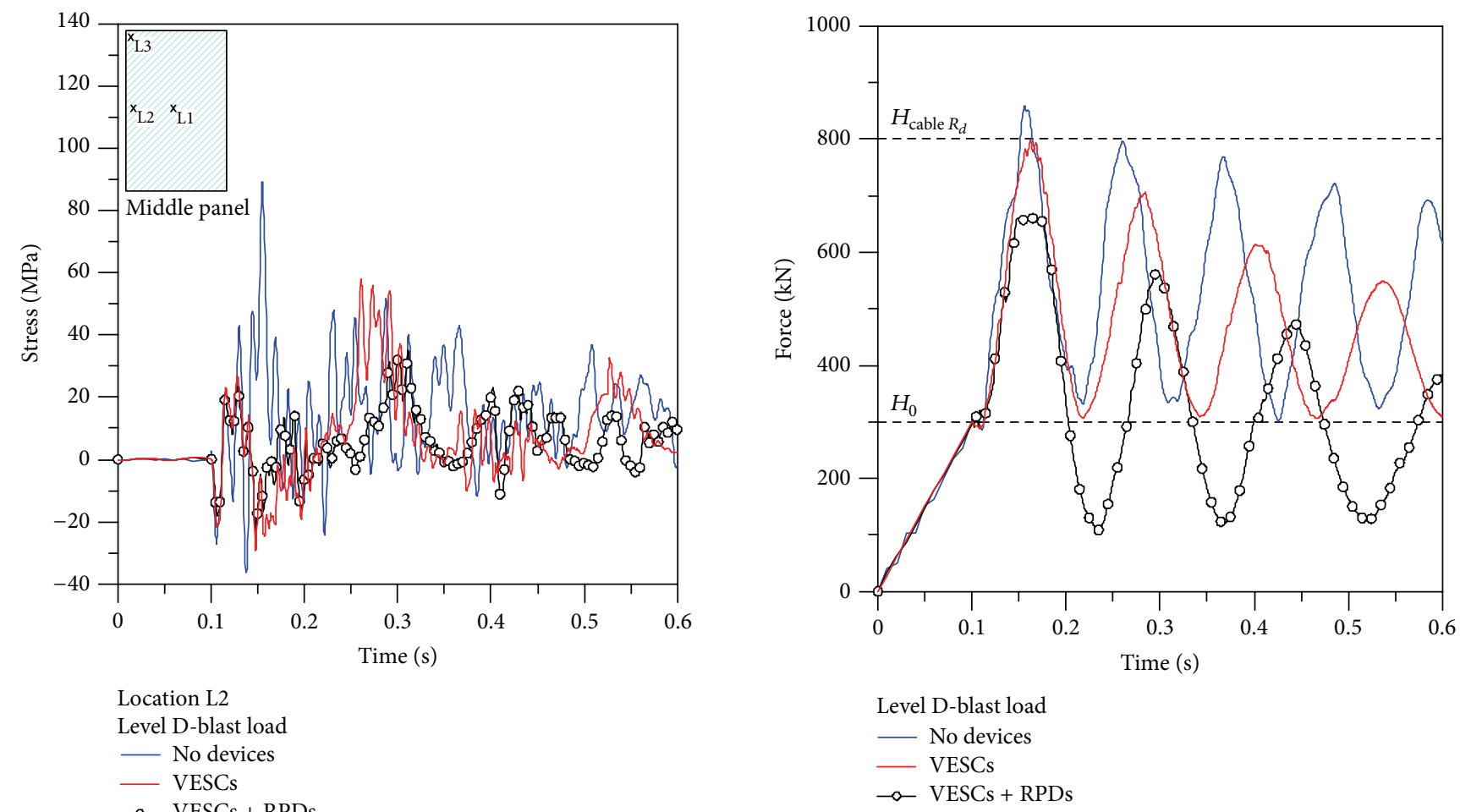
time (ABAQUS). Location L2.

FIGURE 10: Maximum axial force in the cables as a function of time

(ABAQUS).

FIGURE 9: Tensile stresses in the middle glass panel as a function of time (ABAQUS). Location L3.

\footnotetext{
FIgURE 8: Tensile stresses in the middle glass panel, as a function of

Level D-blast load

- No devices

- VESCs

$\multimap$ VESCs + RPDs
}

Location L2 


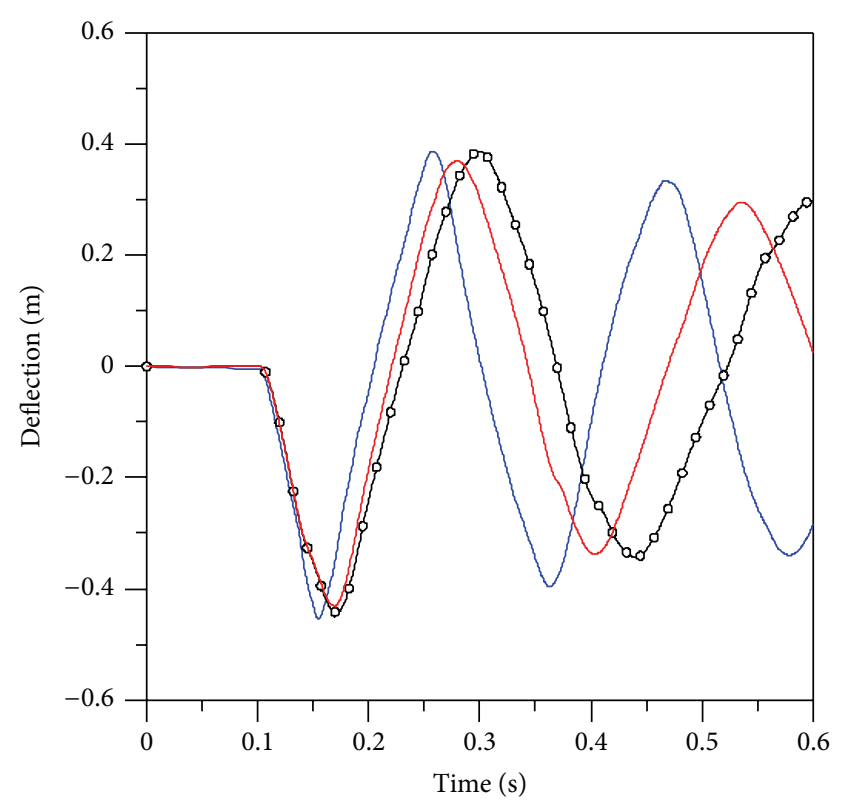

Level D-blast load

- No devices

— VESCs

$\multimap$ VESCs + RPDs

FIGURE 11: Midspan cable deflection as a function of time (ABAQUS).

VESCs manifest their structural effectiveness in the capability of introducing additional deformability/dissipative capabilities in the studied curtain wall [16]. As a result, as it would be expected, major structural benefits can be observed in the glass panes (Figures 7-9). The introduction of VESCs of appropriate mechanical properties does not modify the distribution of tensile stresses in them (the first peak occurs at the centre of the middle panel) but evidently allows to reduce their intensity. As a consequence, the first peak of tensile stress in $\mathrm{L} 1$ is equal to $\sigma_{\text {glass, } \max }=85.73 \mathrm{MPa}$ (Figure 7 and Table 2, $\left.\Delta \sigma_{\text {glass, } \max }=-38 \%\right)$. Optimal results can be observed also at locations L2 and L3, where the glass panel is directly connected to viscoelastic devices and the beneficial effects of the proposed mechanism are maximized (Figures 8 and 9 and Table $2 ; \Delta \sigma_{\text {glass, } \max }=-35 \%$ at location L2 and $\Delta \sigma_{\text {glass, } \max }=-42 \%$ at location L3). It is also interesting to notice that VESCs allow to strongly cut down the axial forces in the bearing cables $\left(H_{\text {cable, } \max }=798 \mathrm{kN}\right.$, with $\Delta H_{\text {cable,max }}=-7 \%$; Figure 10 and Table 3), and at the same time to preserve the initial pretension force $H_{0}\left(H_{\text {cable,min }}=\right.$ $306 \mathrm{kN}=1.02 \mathrm{H}_{0}$, Table 3, Figure 10). Consequently, the midspan cable deflection of the façade module equipped by VESCs results slightly reduced by the beneficial viscoelastic mechanism (Figure 11 and Table $3 ; u_{\text {cable, } \max }=0.41 \mathrm{~m}$, with $\left.\Delta u_{\text {cable, } \max }=-7 \%\right)$.

Numerical simulations allowed to notice that the simultaneous introduction in the studied façade module of VESCs and RPDs can improve significantly the dynamic response of the glazing system, strongly mitigating the effects of a high-level air blast load. Undoubtedly, as highlighted in the previous sections, RPDs can activate only if the maximum axial forces occurring in them are higher than the sliding force $F_{s}$. As a result, in presence of low-level explosions or ordinary dynamic loads, the structural components of the studied façade module are protected only by VESCs.

As proposed in Figures 7-9 and Table 2, when RPDs opportunely designed are used in combination with VESCs, no significant modification can be observed in terms of maximum values of tensile stress occurring in the glass panels, especially if these results are compared with the response of the façade module equipped only by VESCs. Nevertheless, due to the modification of the fundamental period of vibration of the glazing system equipped by VESCs and RPDs, noticeable modifications can be seen in terms of distribution of tensile stresses on the glass surface (Figures 7-9). A similar result does not restrict the validity of RPDs. The major objective of RPDs consists in fact in controlling the maximum pretension forces in the cables; therefore, only VESCs contribute in preserving the glass sheets from cracking.

As proposed in Figure 10, the use of multiple dissipative devices strongly reduces the maximum axial forces occurring in the cables $\left(H_{\text {cable, } \max }=658 \mathrm{kN}, \Delta H_{\text {cable, } \max }=-29 \%\right)$. A significant loss of initial pretension occurs in the bearing systems, since the effectiveness of RPDs necessary implies a drop in the initial pretension. In general, the major is the loss of pretension and the major should be the increasing of the façade deflection, thus, the possibility of collapse for the façade module deprived of an efficient bracing system. In this context, the combined use of RPDs and VESCs exploits the effectiveness of the multiple dissipative mechanisms. As proposed in Figure 11, the deflection of the façade module equipped by VESCs and RPDs slightly increases ( $u_{\text {cable, } \max }=0.44 \mathrm{~m}$ ) because of the loss of pretension due to RPDs $\left(H_{\text {cable,min }}=115 \mathrm{kN}=0.36 H_{0}\right)$. Nevertheless, since the façade can be considered subjected to a "reduced" blast impulse, the loss of initial pretension is not associated with deflections in the façade higher than the deflections occurring in absence of dissipative devices (Table 2).

In conclusion, the glass panels can be strongly mitigate due to VESCs, whereas the bearing cables can be protected from elevated axial forces by RPDs, an in minor part by VESCs.

Due to the introduction of VESCs and RPDs, also the energy balance of the studied façade module strongly modifies. As it would be expected, if the façade module is not equipped by devices, the maximum elastic energy is stored by the bearing cables (Figure 12), whereas its contribution in glass panels or connectors is negligible. In the same circumstance, the glass panels store the major term of kinetic energy, as highlighted in Figure 12. In addition, in absence of VESCs or RPDs, dissipation of the external impulse due to blast can occur only due to aeroelastic or structural damping. As highlighted in FE-modeling description, a total damping ratio $\xi_{\text {TOT }}=2.9 \%$ was taken into account.

When VESCs are introduced in the glazing system to replace the conventional spider connectors, an important improvement of the damping capabilities of the façade module can be noticed (Figure 13). Their strong dissipative 

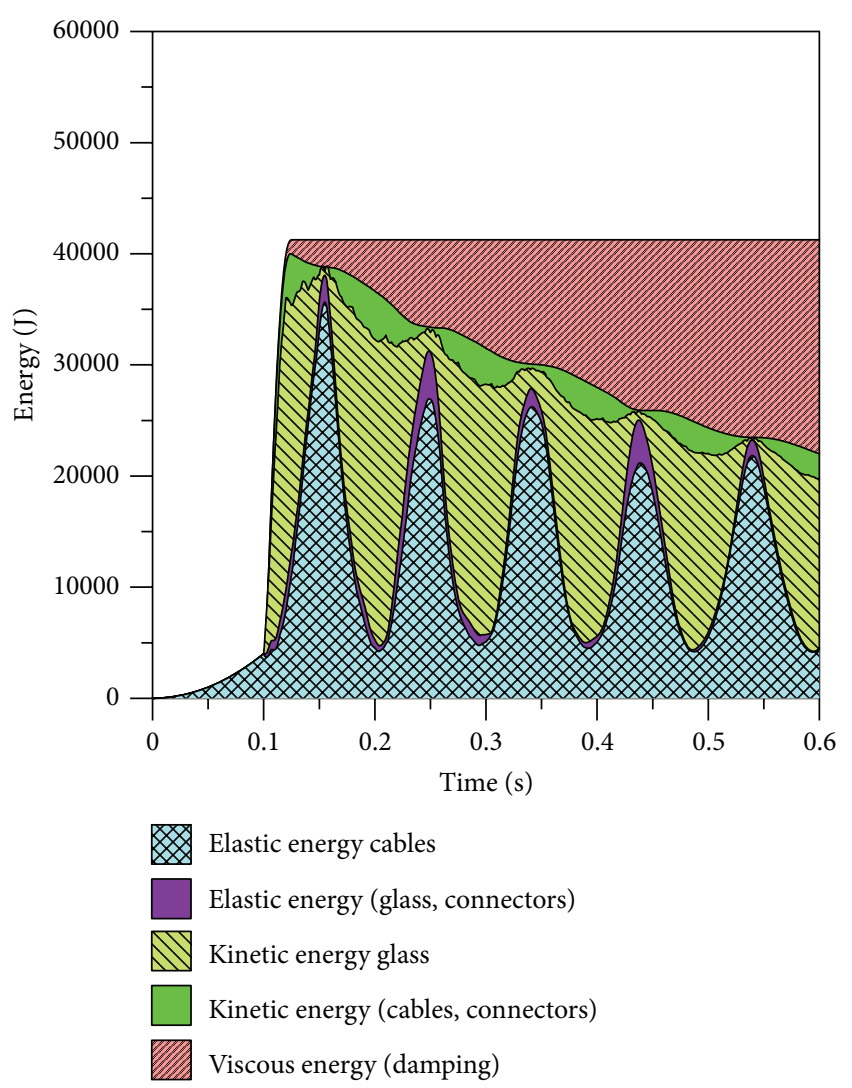

FIGURE 12: Energy terms for the façade-module not equipped by devices (ABAQUS).

contribution implies an appreciable reduction of elastic and kinetic energies stored by the cables and the glass panels. In fact, just because of the working mechanism of VESCs, the façade module can be considered subjected to a "reduced" impulse of blast load. This specific aspect should be taken into account in the dimensioning of RPDs. If VESCs and RPDs are used simultaneously to mitigate the façade-module, in fact, the additional dissipative capabilities of RPDs can be considered applied to a glazing system subjected not to the total impulse of explosion $I_{\mathrm{TOT}}$ but to a minor impulsive blast load. As a result, due to the sliding of the metallic surfaces constituting a typical frictional device, an additional plastic dissipation can be taken into account, with further obvious benefits for the bearing cables and the glass panels (Figure 14). To maximize the effectiveness of VESCs and RPDs, the dissipative devices should be designed and calibrated with attention. Nevertheless, simple energy consideration could be useful in a first dimensioning of the proposed mechanisms as proposed in the following sections.

\section{Maximum Effects of Blast Loading and Preliminary Design of Devices}

The maximum effects on the studied façade due to the design air blast load can be estimated by simplifying the multi-degree-of-freedom (MDOF) cable-supported
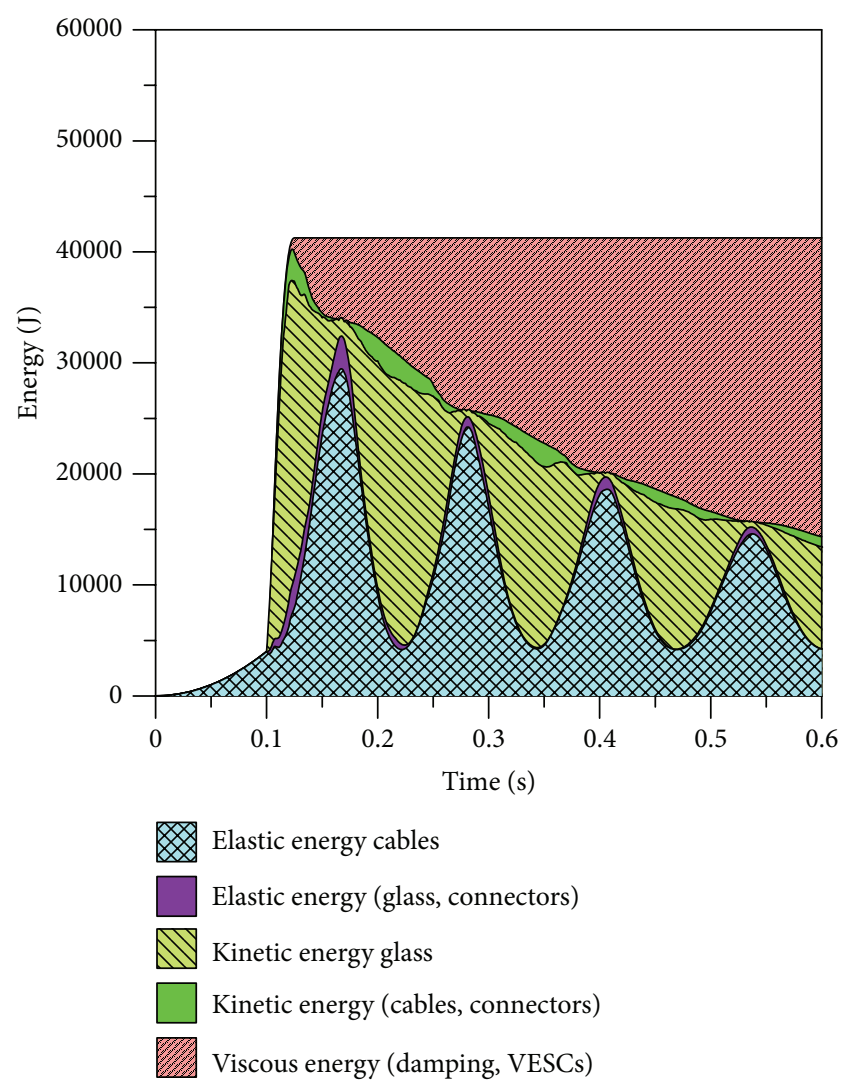

FIGURE 13: Energy terms for the façade-module equipped by VESCs (ABAQUS).

façade with an equivalent single-degree-of-freedom system (SDOF) $[16,17]$. Based on simple energy considerations, the maximum deflection and velocity of the oscillating glazing system, as well as the maximum axial forces occurring in the bearing cables, can be known. The estimated maximum effects of explosion do not allow taking into account the maximum tensile stresses occurring in the glass panels; therefore, additional numerical simulations should be performed. Nevertheless, they could constitute a starting point for the dimensioning of VESCs, as well as for the definition of the sliding force $F_{s}$ characterizing the cyclical response of RPDs.

4.1. Dynamic Response of the Façade Not Equipped by Devices. Let us consider the dynamic parameters of a SDOF system equivalent to the examined cable-supported façade module. The equivalent mass $m^{*}$, stiffness $k^{*}$, and fundamental period $T_{0}^{*}$ of vibration can be expressed as $[16,17]$

$$
\begin{gathered}
m^{*}=\frac{16 M}{30}, \\
k^{*}=\frac{16 H}{3 l_{\text {cable }}}, \\
T_{0}^{*}=2 \pi \sqrt{\frac{m^{*}}{k^{*}}}=2 \pi \sqrt{\frac{M l_{\text {cable }}}{10 H} .}
\end{gathered}
$$


TABLE 4: Comparison of numerical and analytical results for the façade-module not equipped by devices.

\begin{tabular}{lccc}
\hline No devices & & High-level blast load (D-GSA) \\
& ABAQUS M01 FE-model & Analytical procedure & $0.28(4)$ \\
Fundamental period $T_{0}[\mathrm{~s}]$ & 0.26 & $0.44(7)$ & 1.08 \\
Max. displacement $u_{\max }[\mathrm{m}]$ & 0.44 & $17.58(8)$ & 1.00 \\
Max. velocity $\dot{u}_{\max }[\mathrm{m} / \mathrm{s}]$ & 13.96 & $951(5)$ & 1.26 \\
Max. pretension $H_{\max }[\mathrm{kN}]$ & 858 & 1.11 \\
\hline
\end{tabular}

$R=$ analytical/numerical results.

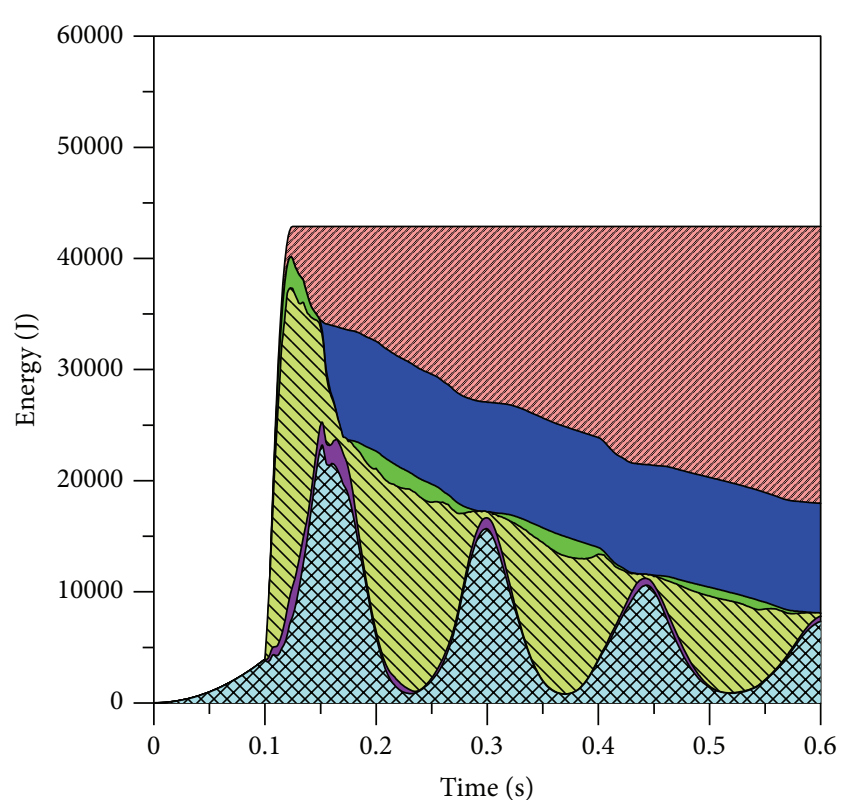

Elastic energy cables

Elastic energy (glass, connectors)

MV Kinetic energy glass

Kinetic energy (cables, connectors)

Viscous energy (damping, VESCs)

Plastic energy (RPDs)

Figure 14: Energy terms for the façade-module equipped by multiple devices (VESCs and RPDs, ABAQUS).

In (3) and (4), $l_{\text {cable }}$ is the cable length, $M=668 \mathrm{Kg}$ is the total mass, and $H=H_{0}$ is the initial pretension force affecting the cables. Due to the incoming impulse $I_{\mathrm{TOT}}$ associated with the design blast load, the maximum pretension force in cables abruptly and significantly increases, reaching a maximum value approximately equal to

$$
H=H_{\max }=H_{0}+H_{\text {blast }},
$$

where

$$
H_{\text {blast }}=\frac{8}{3} \frac{E_{\text {cable }} A_{\text {cable }}}{l_{\text {cable }}^{2}} u_{\text {max }}^{2}
$$

$E_{\text {cable }}$ is the Young's modulus of harmonic steel constituting the cables (Table 1 ), and $u_{\max }$ is the maximum deflection of the façade due to the design explosion. Rationally, to predict the maximum deflection $u_{\max }$ and velocity $\dot{u}_{\max }$ reached by the oscillating façade module, simple energy considerations can be taken into account, leading to $[16,17]$

$$
\begin{gathered}
u_{\max }=\sqrt{\frac{I_{\mathrm{TOT}}^{2}}{M k^{*}}}=I_{\mathrm{TOT}} \sqrt{\frac{16}{30 m^{*} k^{*}}}, \\
\dot{u}_{\max }=\sqrt{\frac{I_{\mathrm{TOT}}^{2}}{M m^{*}}}=\frac{I_{\mathrm{TOT}}}{m^{*}} \sqrt{\frac{16}{30}} .
\end{gathered}
$$

As result, to properly estimate $u_{\max }$ an iterative process should be performed by iteratively substituting (5) in (3), until the obtained displacement $u_{\max }$ (7) remains constant.

Numerical and analytical comparisons summarized in Table 4 confirm the accuracy of the proposed approach.

4.2. Dynamic Response of the Façade with VESCs. The façade module equipped by VESCs can be assimilated to an equivalent SDOF system having mass $m^{*}(2)$ and equivalent stiffness/dissipative properties $\left(k_{\mathrm{TOT}}^{*}, c_{\mathrm{TOT}}^{*}\right)$ defined as a function of the characteristics of each viscoelastic device $\left(k_{d}, c_{d}[22\right.$, 23]). Specifically, $k_{\mathrm{TOT}}^{*}$ can be estimated as the equivalent stiffness of a SDOF system in which the cable of rigidity $k^{*}$ (3) works in series with VESCs as follows:

$$
k_{\mathrm{TOT}}^{*}=\frac{1}{\left(1 / k_{\mathrm{VE}}^{*}\right)+\left(1 / k^{*}\right)},
$$

where

$$
k_{\mathrm{VE}}^{*}=\frac{8}{15} \frac{n k_{d}}{i_{\mathrm{VE}}} l_{\text {cable }}
$$

the total stiffness provided by the series of VESCs, $i_{\mathrm{VE}}$ the distance between VESCs, and $n$ the number of viscoelastic devices in each VESC (in presence of four-hole and two-hole connectors, a medium value should be considered for $n$ ).

Based on (9), the fundamental period of vibration results in

$$
T_{0, \mathrm{VE}}^{*}=2 \pi \sqrt{\frac{m^{*}}{k_{\mathrm{TOT}}^{*}}} \geq T_{0}^{*},
$$

where $T_{0}^{*}$ as given by (4).

At the same time, the total damping coefficient of the SDOF system equipped by VESCs is

$$
\xi_{\mathrm{TOT}}^{*}=\frac{c_{\mathrm{TOT}}^{*}}{2 m^{*} \omega_{0, \mathrm{VE}}^{*}},
$$


TABLE 5: Comparison of numerical and analytical results for the façade-module with VESCs.

\begin{tabular}{|c|c|c|c|}
\hline \multirow{2}{*}{ VESCs } & \multicolumn{3}{|c|}{ High-level blast load (D-GSA) } \\
\hline & ABAQUS FE-model & Analytical procedure & $R[-]$ \\
\hline Max. displacement $u_{\max }[\mathrm{m}]$ & 0.41 & $0.39(7)$ & 0.95 \\
\hline Max. velocity $\dot{u}_{\max }[\mathrm{m} / \mathrm{s}]$ & 11.17 & $14.35(8)$ & 1.28 \\
\hline Max. increment of pretension $\left(H_{\text {blast }}\right)_{\text {red }}[\mathrm{kN}]$ & 498 & $510(6)$ & 1.02 \\
\hline Max. total pretension $\left(H_{\max }\right)_{\mathrm{red}}[\mathrm{kN}]$ & 798 & $810(5)$ & 1.02 \\
\hline Max. sliding of VESCs $s_{\max }^{\mathrm{VESC}}[\mathrm{m}]$ & 0.0450 & $0.0452(16)$ & 1.00 \\
\hline Max. shear strain ratio of VESCs $\gamma_{\max }^{\mathrm{VESC}}[-]$ & 2.25 & 2.26 & 1.00 \\
\hline
\end{tabular}

$R=$ analytical/numerical results.

where $\omega_{0, \mathrm{VE}}^{*}$ as the fundamental frequency of vibration of the system (11) and

$$
c_{\mathrm{TOT}}^{*}=\frac{1}{\left(1 / c_{\mathrm{VE}}^{*}\right)+\left(1 / c^{*}\right)} \text {. }
$$

In (13),

$$
c^{*}=2 M \xi_{\mathrm{TOT}} \omega_{0}^{*}
$$

represents the damping ratio of the conventional façade module $\left(\xi_{\text {TOT }}=2.9 \%\right)$, $\omega_{0}^{*}$ is the fundamental frequency of vibration (4), and $M=668 \mathrm{Kg}$ the corresponding total mass.

In addition

$$
c_{\mathrm{VE}}^{*}=\frac{8}{15} \frac{n c_{d}}{i_{\mathrm{VE}}} l_{\text {cable }}
$$

represents the total damping ratio $c_{\mathrm{VE}}^{*}$ of VESCs.

In these hypotheses, once the equivalent dynamic parameters of the SDOF system are known, it is possible to estimate the maximum effects of a given explosion on the studied glazing system with VESCs. However, a further iterative procedure should be performed. The maximum deflection $u_{\text {TOT, max }}$ of the SDOF system should be in fact calculated by means of (7) by substituting $k^{*}(3)$ with $k_{\mathrm{TOT}}^{*}(9)$.

It is important to notice that $u_{\mathrm{TOT} \text {, max }}$ is higher than the effective deflection of the façade module, since calculated on the basis of the total impulse $I_{\text {TОT }}$. Nevertheless, its estimation is fundamental in determining the sliding of viscoelastic devices when the explosion occurs.

Consider

$$
s_{\max }^{\mathrm{VESC}}=\frac{u_{\mathrm{TOT}, \max } k^{*}}{k_{\mathrm{VE}}^{*}+k^{*}} .
$$

To avoid the cracking of the viscoelastic layer due to explosion, $s_{\max }^{\mathrm{VESC}}$ should satisfy the limit condition $\gamma_{\max }^{\mathrm{VESC}}=$ $s_{\max }^{\mathrm{VESC}} / h^{\mathrm{VESC}}=2 \div 2.5$.

Based on (16), the effective maximum elastic energy stored by VESCs can also be estimated as

$$
E_{\mathrm{elastic}}^{\mathrm{VE}}=\frac{1}{2} k_{\mathrm{VE}}^{*}\left(s_{\max }^{\mathrm{VESC}}\right)^{2} .
$$

therefore, it is possible to assert that the total impulse $I_{\mathrm{TOT}}$ of the explosion does not entirely transfers through VESCs to the cables, but only a reduced impulse $I_{\text {red }}$ affects them as follows:

$$
I_{\text {red }}=I_{\mathrm{TOT}}-\Delta I_{\mathrm{VE}}=I_{\mathrm{TOT}}-\sqrt{E_{\text {elastic }}^{\mathrm{VE}} 2 M} .
$$

In these hypotheses, a third iterative procedure should be carried out to estimate the maximum cable deflection and the final pretension due to the "effective" explosion of impulse $I_{\text {red }}$ (18) by taking into account the additional deformability/dissipative capabilities of VESCs. To calculate the real cable deflection $u_{\max }(7)$, it is sufficient to substitute $I_{\text {TOT }}$ with $I_{\text {red }}(18)$ and $k^{*}$ (3) with $k_{\text {TOT }}^{*}(9)$. The corresponding velocity is given by (8), with $I_{\text {TOT }} \equiv I_{\text {red }}(18)$, whereas the maximum total pretension $\left(H_{\max }\right)_{\text {red }}$ occurring in the mitigated cables can be calculated with (5), as the sum of the initial pretension force $\mathrm{H}_{0}$ and the increasing of pretension $\left(H_{\text {blast }}\right)_{\text {red }}(6)$ due to the reduced impulse $I_{\text {red }}$. As proposed in Table 5, also in this circumstance numerical predictions are in good agreement with analytical estimations.

4.3. Dynamic Response of the Façade with VESCs and RPDs. If RPDs are used in combination with VESCs, an additional frictional dissipation capability is introduced in the conventional glazing system. The effectiveness of RPDs directly depends on the amount of their sliding. The amount of plastic energy dissipated by friction is in fact as follows:

$$
E_{\text {friction }}^{\mathrm{RPD}}=F_{s} s_{\max }^{\mathrm{RPD}},
$$

where $F_{s}$ is the sliding force of RPDs and $s_{\max }^{\mathrm{RPD}}$ is their maximum sliding due to the design explosion.

Nevertheless, the optimal solution should be identified by taking into account the loss of initial pretension in the bearing cables typically associated with the effectiveness of the proposed frictional mechanism. In general, the maximum sliding of RPDs should not exceed the limit [17] as follows:

$$
s_{\text {limit }}^{\mathrm{RPD}}=\frac{H_{0}}{k_{\text {cable }}},
$$

which represents the sliding associated to the complete loss of pretension in the cables. At the same time, the optimal value for the sliding force $F_{s}$ should be estimated not ignoring that the maximum increment of pretension in the cables $\left(H_{\max }\right)_{\text {red }}$ due to the design explosion is already mitigated by VESCs (third iterative procedure, as discussed in the previous 
TABLE 6: Comparison of numerical and analytical results for the façade-module with VESCs and RPDs.

\begin{tabular}{|c|c|c|c|}
\hline \multirow{2}{*}{ VESCs + RPDs } & \multicolumn{3}{|c|}{ High-level blast load (D-GSA) } \\
\hline & ABAQUS FE-model & Analytical procedure & $R[-]$ \\
\hline Max. sliding of RPDs $s_{\max }^{\mathrm{RPD}}[\mathrm{m}]$ & 0.0165 & 0.0159 & 0.97 \\
\hline Max. increment of pretension $\left(H_{\text {blast }}\right)_{\text {red }}[\mathrm{kN}]$ & 358 & 350 & 0.98 \\
\hline Max. total pretension $\left(H_{\max }\right)_{\text {red }}[\mathrm{kN}]$ & 658 & $650\left(\right.$ design load $\left.F_{s}\right)$ & 0.98 \\
\hline Residual pretension $H_{\text {final }}[\mathrm{kN}]$ & 115 & $120(22)$ & 1.05 \\
\hline Max. displacement $u_{\max }[\mathrm{m}]$ & 0.44 & $0.43(7)$ & 0.97 \\
\hline
\end{tabular}

$R=$ analytical/numerical results.

section). In these hypotheses, a rational value for $F_{s}$ should be preliminary assumed equal to $F_{s} \cong 0.85\left(H_{\max }\right)_{\text {red }}$. Once the force $F_{s}$ is estimated, the corresponding sliding in the frictional device due to the occurring explosion can be calculated as [17]

$$
\begin{aligned}
& s_{\max }^{\mathrm{RPD}} \\
& \quad=\frac{1}{2 F_{s} k_{\text {cable }}}\left[\left(H_{\text {blast }}\right)_{\text {red }}^{2}+2 H_{0}\left(H_{\text {blast }}\right)_{\text {red }}-\left(F_{s}^{2}-H_{0}^{2}\right)\right] .
\end{aligned}
$$

Therefore $s_{\max }^{\mathrm{RPD}}$ should not exceed the value $s_{\text {limit }}^{\mathrm{RPD}}(20)$.

In the studied example, as previously asserted, a value of $F_{s}=650 \mathrm{kN}=0.80\left(H_{\max }\right)_{\text {red }}<0.85\left(H_{\max }\right)_{\text {red }}$ was taken into account for the sliding force of frictional devices, since performed simulations demonstrated that this value is associated to major benefits in the investigated facademodule.

As result, the maximum sliding of RPDs due to the effective blast load results approximately equal to $s_{\max }^{\mathrm{RPD}} \cong$ $15.9 \mathrm{~mm}$ (21); therefore, not only it evidently is lower than the limit acceptable sliding $s_{\text {limit }}^{\text {RPD }}=26.5 \mathrm{~mm}(20)$, but also it agrees well with numerical predictions (Table 6). In these hypotheses, also the residual pretension in each cable $H_{\text {final }}$ after the occurring of explosion and the involvement of VESCs + RPDs, given by

$$
H_{\text {final }}=H_{0}-k_{\text {cable }} s_{\max }^{\mathrm{RPD}},
$$

which is in good agreement with numerical results (Table 6 or Figure 10).

The plastic energy $E_{\text {friction }}^{\mathrm{RPD}}$ dissipated by the adopted RPDs (19) is equal to $E_{\text {friction }}^{\mathrm{RPD}}=10335 \mathrm{~J}$, and this value finds again a good correspondence with the numerical energy balance proposed in Figure 14 (blue pattern), where it can be noticed that $\left(E_{\text {friction }}^{\mathrm{RPD}}\right)_{\mathrm{ABAQUS}} \cong 10000 \mathrm{~J}$.

At last, due to the combined interaction of optimally designed VESCs and RPDs, the maximum deflection $u_{\max }$ of the façade module can be approximately estimated by (7), as proposed in Table 6 . The reference SDOF system can be in fact characterized by an equivalent stiffness $k_{\text {TOT }}^{*}$ given by (9), in which the stiffness of the façade module not equipped by devices $k^{*}$ (3) can be directly estimated by assuming $H=$ $H_{\text {max }}=F_{s}$ (with $H_{\text {blast }}=F_{s}-H_{0}$ the expected maximum increment of pretension), due to designed RPDs. At the same time, due to adopted VESCs, the façade can be considered subjected to a "reduced" design explosion of total impulse $I_{\text {red }}$ (18).

4.4. Design Approach. Based on the assumptions proposed in the previous sections, the following steps could help designers to optimize the effectiveness of VESCs and RPDs and the dynamic response of the studied cable-supported façade.

(1) Preliminary design of the façade module and first estimation of maximum blast effects.

(a) Choice of the design air blast load (definition of the total impulse $I_{\mathrm{TOT}}$ due to explosion)

(b) preliminary design of the façade-module (cables diameter, initial pretension, and glass thickness), and

(c) simplified dynamic analysis of the façademodule without devices (first iterative procedure): evaluation of maximum displacement $u_{\max }(7)$, velocity $\dot{u}_{\max }(8)$, and pretension $H_{\text {max }}$ (5).

(2) Introduction of VESCs as follows.

(a) Choice of appropriate values of rigidity $k_{d}$ and damping ratio $c_{d}$ for each viscoelastic device;

(b) evaluation of the dynamic parameters of the equivalent SODF system with VESCs $\left(k_{\mathrm{TOT}}^{*}(9)\right.$, $T_{0, \mathrm{VE}}^{*}(11)$, and $\left.\xi_{\mathrm{TOT}}^{*}(12)\right)$;

(c) estimation of the total cable deflection $\boldsymbol{u}_{\mathrm{TOT} \text {,max }}$ (7) and the sliding $s_{\max }^{\mathrm{VESC}}$ of viscoelastic devices (16) (second iterative procedure), and the maximum sliding $s_{\max }^{\mathrm{VESC}}$ should not exceed the limit $\gamma_{\max }^{\mathrm{VESC}}=2 \div 2.5$, and if this condition is not satisfied, the viscoelastic devices are not adequately dimensioned to resist the design air blast load (point 2a);

(d) calculation of the maximum elastic energy $E_{\text {elastic }}^{\mathrm{VE}}$ stored by VESCs (17);

(e) estimation of the effective impulse $I_{\text {red }}$ affecting the façade module with VESCs (18); and

(f) evaluation of the maximum effects due to $I_{\text {red }}$ on the façade module with VESCs (third iterative procedure): maximum deflection $u_{\max }$ (7), velocity $\dot{u}_{\max }(8)$, and pretension $\left(H_{\max }\right)_{\text {red }}(5)$. 
(3) Introduction of RPDs.

(a) Estimation of the limit sliding $s_{\text {limit }}^{\mathrm{RPD}}(20)$ of RPDs associate with the complete loss of pretension in the cables;

(b) choice of the optimal value of sliding force $F_{s}$, and Rationally, the sliding force should be assumed approximately equal to $F_{s} \cong 0.85$ $\left(H_{\max }\right)_{\text {red }}$, with $\left(H_{\max }\right)_{\text {red }}$ calculated at point $2 \mathrm{f}$; and

(c) Check the maximum sliding of frictional devices $s_{\max }^{\mathrm{RPD}}(21)$ due to the "effective" blast impulse $I_{\text {red }}$, and the maximum sliding $s_{\max }^{\mathrm{RPD}}$ should not exceed the limit sliding $s_{\text {limit }}^{R P D}$ (point $3 \mathrm{a}$ ), and if not, the assumed value of sliding force $F_{s}$ is not adequate (point $3 \mathrm{~b}$ ).

(4) FE modelling of the façade-module with VESCs and RPDs.

(5) Verification of the glazing system.

Certainly, a similar design procedure depends on the variability of the design blast loading and the mechanical parameters characterizing the dynamic behaviour of the presented VESCs and RPDs. In addition, once the RPDs are introduced at the cable ends and used in combination with VESCs, no analytical formulations can be used to predict the "effective" response of the façademodule equipped by multiple devices. Consequently, additional numerical simulations should be performed. In any case, as proposed in this work, it should not be ignored that the use of multiple devices allows strongly improving the dynamic response of a cablesupported façade. In addition, the proposed design approach provides analytical results that are in good agreement with numerical predictions as proposed in previous sections.

\section{Conclusions}

The criticalities of a cable-supported façade subjected to highlevel blast wave pressures were investigated by means of a sophisticated numerical model. Since the glass panels and the bearing cables present typical brittle-elastic behaviour, the occurring in them of elevated tensile stresses should be avoided to preserve the stability of the curtain wall. At the same time, the maximum deflection of the façade should be limited to safeguard the integrity of the point-supported glass sheets. Because of these reasons, based on numerical results of previous efforts, the effects of multiple dissipative devices were analyzed numerically. The proposed devices consist in viscoelastic spider connectors (VESCs) introduced in the points of connection between the glass panels and the bearing cables and in additional rigid-plastic frictional devices (RPDs) installed at the top or bottom of the pretensioned cables. As shown in the paper, numerical simulations have been discussed to highlight the structural advantages and energy-dissipation capabilities due to the combined use of multiple dissipative devices. In particular, VESCs cut down the maximum tensile stresses in glass panes due to air blast and reduce axial forces and deflections in the cables. At the same time, the joined use of RPDs allow to furthermore control and limit the maximum pretension forces occurring in the bearing cables, improving the structural effectiveness of single VESCs. At last, simple design rules derived from energy considerations were proposed for a first estimation of the maximum effects of a high-level air blast load and for a preliminary design of the proposed multiple devices.

\section{References}

[1] J. Wei, M. S. Shetty, and L. R. Dharani, "Stress characteristics of a laminated architectural glazing subjected to blast loading," Computers and Structures, vol. 84, no. 10-11, pp. 699-707, 2006.

[2] S. Zhao, L. R. Dharani, and X. Liang, "Analysis of damage in laminated architectural glazing subjected to blast loading," Advances in Structural Engineering, vol. 11, no. 1, pp. 129-134, 2008.

[3] M. V. Seica, M. Krynski, M. Walker, and J. A. Packer, "Analysis of dynamic response of architectural glazing subject to blast loading," Journal of Architectural Engineering, vol. 17, no. 2, pp. 59-74, 2011.

[4] J. Wei, M. S. Shetty, and L. R. Dharani, "Failure analysis of architectural glazing subjected to blast loading," Engineering Failure Analysis, vol. 13, no. 7, pp. 1029-1043, 2006.

[5] J. Wei and L. R. Dharani, "Fracture mechanics of laminated glass subjected to blast loading," Theoretical and Applied Fracture Mechanics, vol. 44, no. 2, pp. 157-167, 2005.

[6] J. Wei and L. R. Dharani, "Response of laminated architectural glazing subjected to blast loading," International Journal of Impact Engineering, vol. 32, no. 12, pp. 2032-2047, 2006.

[7] M. Larcher, G. Solomos, F. Casadei, and N. Gebbeken, "Experimental and numerical investigations of laminated glass subjected to blast loading," International Journal of Impact Engineering, vol. 39, no. 1, pp. 42-50, 2012.

[8] P. Hooper, H. Arora, and J. P. Dear, "Blast and impact resistance of laminated glass structures," in Proceedings of the IMPLAST Symposium on Plasticity and Impact Mechanics, Providence, RI, USA, 2010.

[9] D. C. Weggel and B. J. Zapata, "Laminated glass curtain walls and laminated glass lites subjected to low-level blast loading," Journal of Structural Engineering, vol. 134, no. 3, pp. 466-477, 2008.

[10] D. C. Weggel, B. J. Zapata, and M. J. Kiefer, "Properties and dynamic behavior of glass curtain walls with split screw spline mullions," Journal of Structural Engineering, vol. 133, no. 10, pp. 1415-1425, 2007.

[11] C. Amadio and C. Bedon, "Blast analysis of laminated glass curtain walls equipped by viscoelastic dissipative devices," Buildings, vol. 2, pp. 359-383, 2012.

[12] X. Zhang, H. Hao, and G. Ma, "Parametric study of laminated glass window response to blast loads," Engineering Structures, vol. 56, pp. 1707-1717, 2013.

[13] M. Teich, P. Warnstedt, and N. Gebbeken, "The influence of negative phase loading on cable net facade response," Journal of Architectural Engineering, vol. 18, no. 4, pp. 276-284, 2012.

[14] F. Wellershoff, "Design methods and structural components of blast enhanced façades," in Proceedings of the Challenging Glass 3-International Conference on Architectural and Structural Applications of Glass, F. Bos, C. Louter, R. Nijsse, and F. Veer, Eds., pp. 28-29, IOS Press, Delft, The Netherlands, June 2012. 
[15] F. Wellershoff, G. Lori, M. Zobec, and K. Osterland, "Structural design of blast enhanced cable net facades," in Proceedings of the COST Action TU0905 Mid-Term Conference on Structural Glass, J. Belis, C. Louter, and D. Mocibob, Eds., pp. 121-131, 2013.

[16] C. Amadio and C. Bedon, "Viscoelastic spider connectors for the mitigation of cable-supported façades subjected to air blast loading," Engineering Structures, vol. 42, pp. 190-200, 2012.

[17] C. Amadio and C. Bedon, "Elastoplastic dissipative devices for the mitigation of blast resisting cable-supported glazing façades," Engineering Structures, vol. 39, pp. 103-115, 2012.

[18] GSA-TSO1-2003, "Standard Test Method for Glazing and Window Systems Subject to Dynamic Overpressure Loadings," U.S. General Service Administration, 2003.

[19] ABAQUS, v. 6.10, Computer software, Simulia, Dassault Systemes, Providence, RI, USA.

[20] M. Larcher and G. Solomos, "Laminated glass loaded by air blast waves-experiments and numerical simulations," Tech. Rep. JRC57559, Joint Research Centre, Pubsy, 2010.

[21] R.-Q. Feng, L.-L. Zhang, Y. Wu, and S.-Z. Shen, "Dynamic performance of cable net facades," Journal of Constructional Steel Research, vol. 65, no. 12, pp. 2217-2227, 2009.

[22] M. L. Lai, P. Lu, D. A. Lunsford, K. C. Chang, and K. Kasai, "Viscoelastic damper: a damper with linear or nonlinear material?" in Proceedings of 11th World Conference on Earthquake Engineering, Acapulco, Mexico, 1996.

[23] T. T. Song and G. F. Dargush, Passive Energy Dissipation Systems in Structural Engineering, John Wiley \& Sons, 1997. 

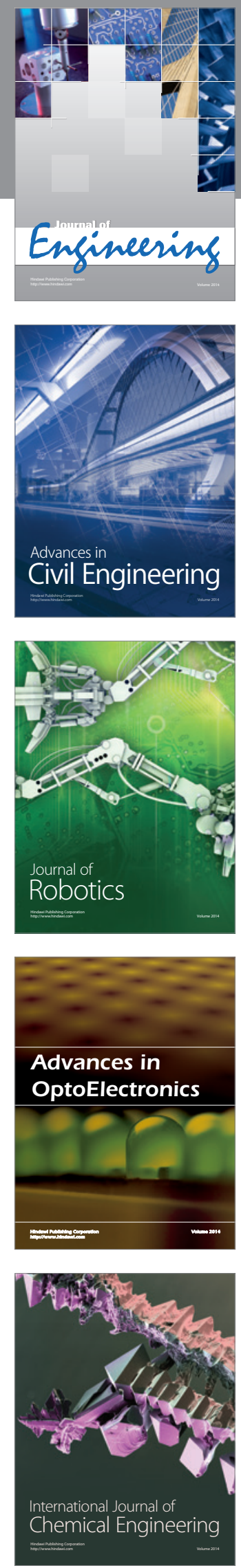

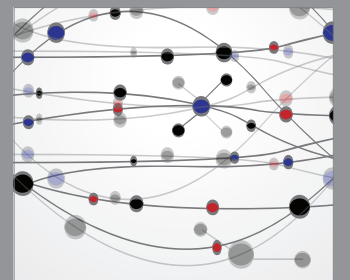

The Scientific World Journal
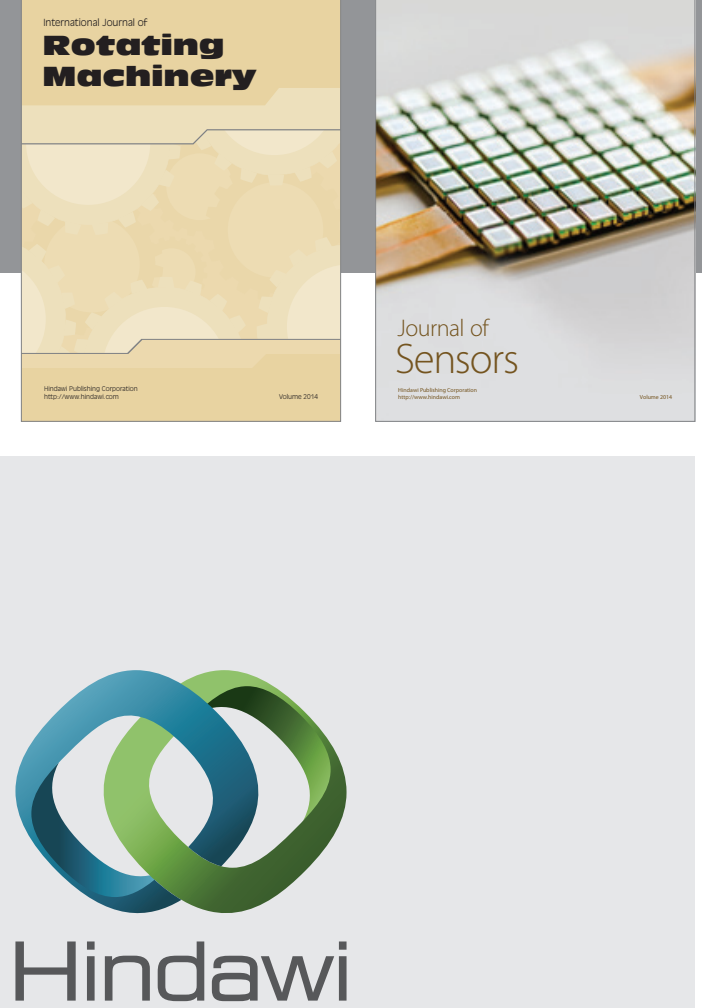

Submit your manuscripts at http://www.hindawi.com
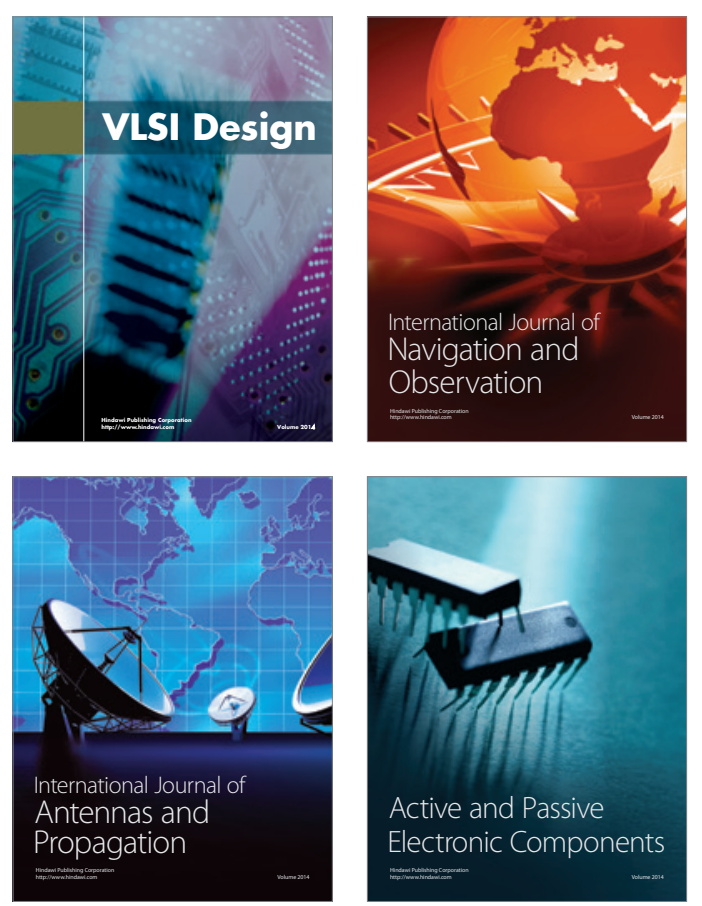
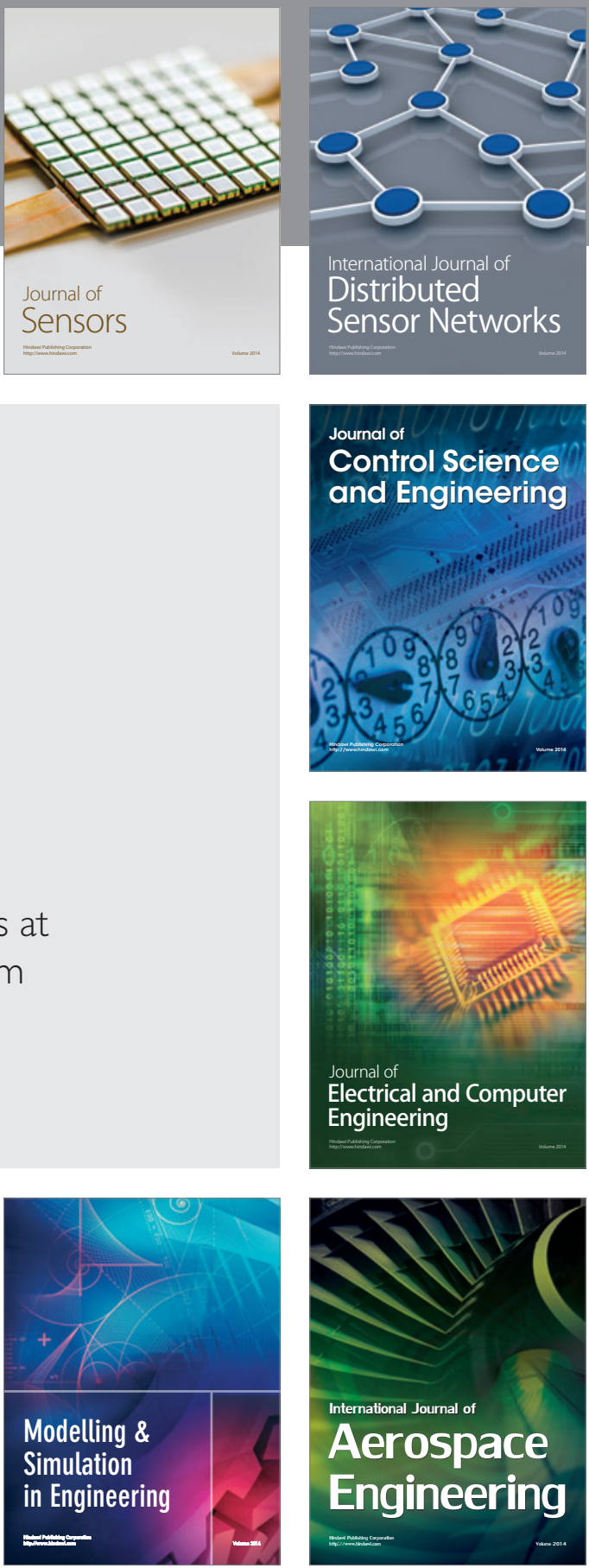

Journal of

Control Science

and Engineering
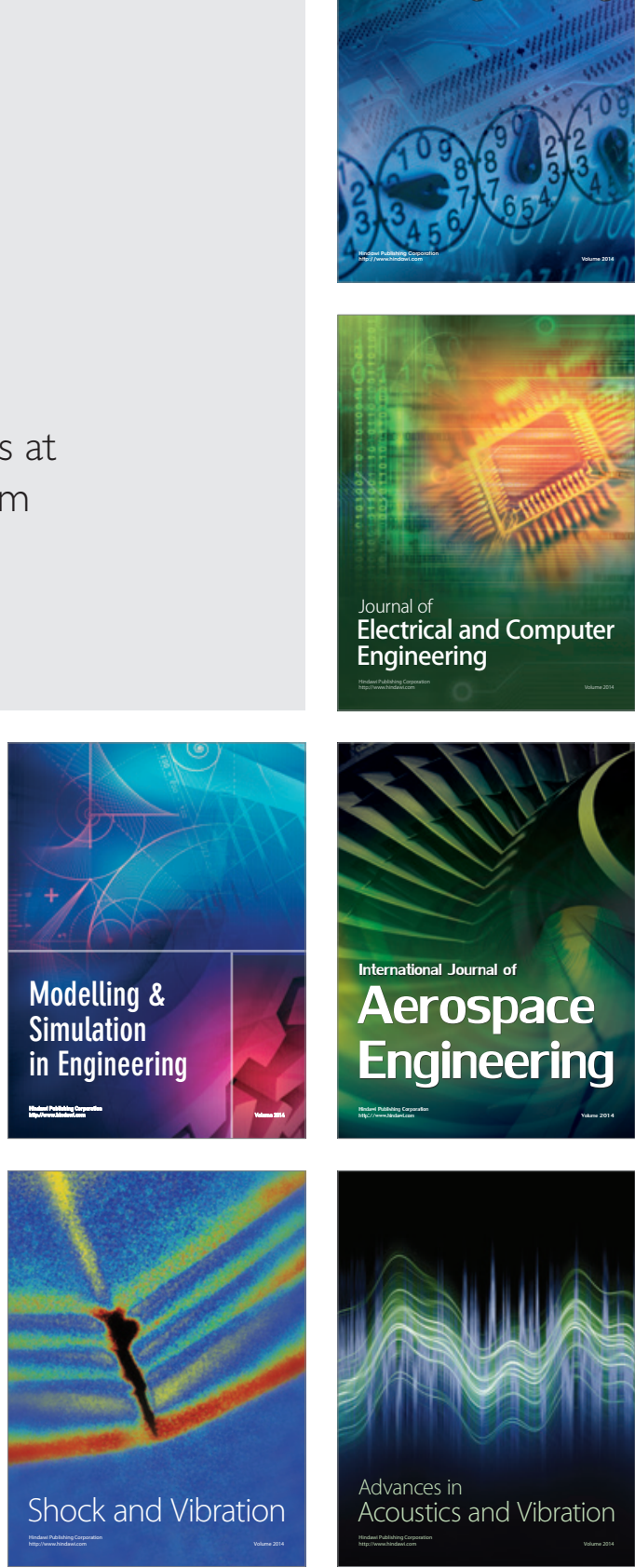